The INL is a

U.S. Department of Energy

National Laboratory

operated by

Battelle Energy Alliance

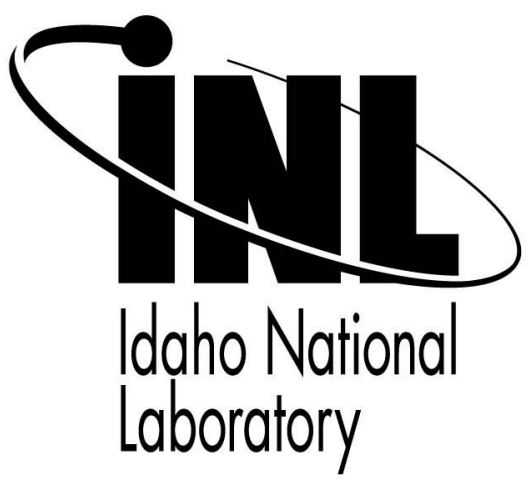

\section{Framework and}

\section{Application for Modeling \\ Control Room Crew \\ Performance at Nuclear \\ Power Plants}

\section{$52^{\text {nd }}$ Annual Meeting of the Human Factors and Ergonomics Society}

\author{
Ronald L. Boring \\ David I. Gertman \\ Tuan Q. Tran \\ Brian F. Gore
}

\section{September 2008}

This is a preprint of a paper intended for publication in a journal or proceedings. Since changes may be made before publication, this preprint should not be cited or reproduced without permission of the author. This document was prepared as an account of work sponsored by an agency of the United States Government. Neither the United States Government nor any agency thereof, or any of their employees, makes any warranty, expressed or implied, or assumes any legal liability or responsibility for any third party's use, or the results of such use, of any information, apparatus, product or process disclosed in this report, or represents that its use by such third party would not infringe privately owned rights. The views expressed in this paper are not necessarily those of the United States Government or the sponsoring agency. 


\title{
FRAMEWORK AND APPLICATION FOR MODELING CONTROL ROOM CREW PERFORMANCE AT NUCLEAR POWER PLANTS
}

\author{
Ronald L. Boring, David I. Gertman, Tuan Q. Tran \\ Idaho National Laboratory \\ Idaho Falls, ID 83415, USA \\ Brian F. Gore \\ San Jose State University Foundation, NASA Ames Research Center \\ Moffett Field, CA 94305, USA
}

\begin{abstract}
This paper summarizes an emerging project regarding the utilization of high-fidelity MIDAS simulations for visualizing and modeling control room crew performance at nuclear power plants. The key envisioned uses for MIDAS-based control room simulations are: (i) the estimation of human error associated with advanced control room equipment and configurations, (ii) the investigative determination of contributory cognitive factors for risk significant scenarios involving control room operating crews, and (iii) the certification of reduced staffing levels in advanced control rooms. It is proposed that MIDAS serves as a key component for the effective modeling of cognition, elements of situation awareness, and risk associated with human performance in next generation control rooms.
\end{abstract}

\section{GENERAL INTRODUCTION}

There is resurgence in interest in the design of next generation nuclear power (NGNP) plants (Boring et al., in press). Future control room designs for nuclear facilities will most certainly incorporate advanced digital technologies, automation, and intelligent systems. Driven by these advances, the concepts of operations may be radically different for such plants than for current generation plants. Design advances are necessary to meet these complex control requirements, reduce staffing and maintenance costs, and reduce the burden of security costs. Prior to any change, however, research is needed to evaluate the impact of these new technologies and operational concepts for their effect on human performance and ultimately plant safety.

While clear guidance exists for assessing current control room technologies (e.g., O'Hara et al., 2002, and O'Hara et al., 2004), there is a need to develop new methods to keep pace with design advances. The US National Research Council noted in 1997 (p. 60):

\footnotetext{
At this time, there is no agreed-upon, effective method for designers, owner-operators, maintainers, and regulators to assess the overall impact of computer-based, human-machine interfaces on human performance in nuclear power plants. What method and approach should be used to assure proper consideration of human factors and human-machine interfaces?
}

This challenge still holds true today. With the onward progression of available technology that may be applied to control rooms, what techniques exist that allow a thorough evaluation of the human factors and safety implications of such implementation? In this paper, we propose the use of human performance modeling as the key component in evaluating NGNP control room technology.

\section{INTRODUCTION TO MIDAS}

The Man-machine Integration Design and Analysis System (MIDAS) is a modeling environment developed by NASA Ames Research Center over a 20-year period (Hart, et al., 2001). MIDAS combines in a single environment a dynamic simulation scenario builder, a three-dimensional graphical environment modeling system, an ergonomically correct virtual human, and a series of cognitive and perceptual models (Gore and Jarvis, 2005). Using this interplay of components, it is possible to create high-fidelity simulations of humans interacting with systems, including human performance modeling over repeated simulation trials.

While MIDAS has to date been used extensively in aerospace to model astronautic crew performance in microgravity, it also holds considerable promise for the simulation of control room scenarios in nuclear power plants. Figure 1 illustrates a mockup of an advanced control room prototype using MIDAS. Note that this particular control room application contains multiple display monitors. One of the most powerful features of MIDAS is that it accounts for information processing and decision making as they relate to perception, attention, visual search and strategy, and response selection. The MIDAS representation of selective attention is modeled on Wickens et al.'s (2004) four-factor theory of attention: salience, effort, expectancy, and value. The visual processing factors modeled in MIDAS include gaze (dwell time), saccadic moments, and field of view. Thus, in our example in Figure 1, the efficacy of operator displays can be assessed as a function of location based upon whether they are likely within the operator's field of view and other factors that can affect the effort component of attention. Within the MIDAS implementation, it is possible to assess the extent to which information is presented that meets the operator's mental model 


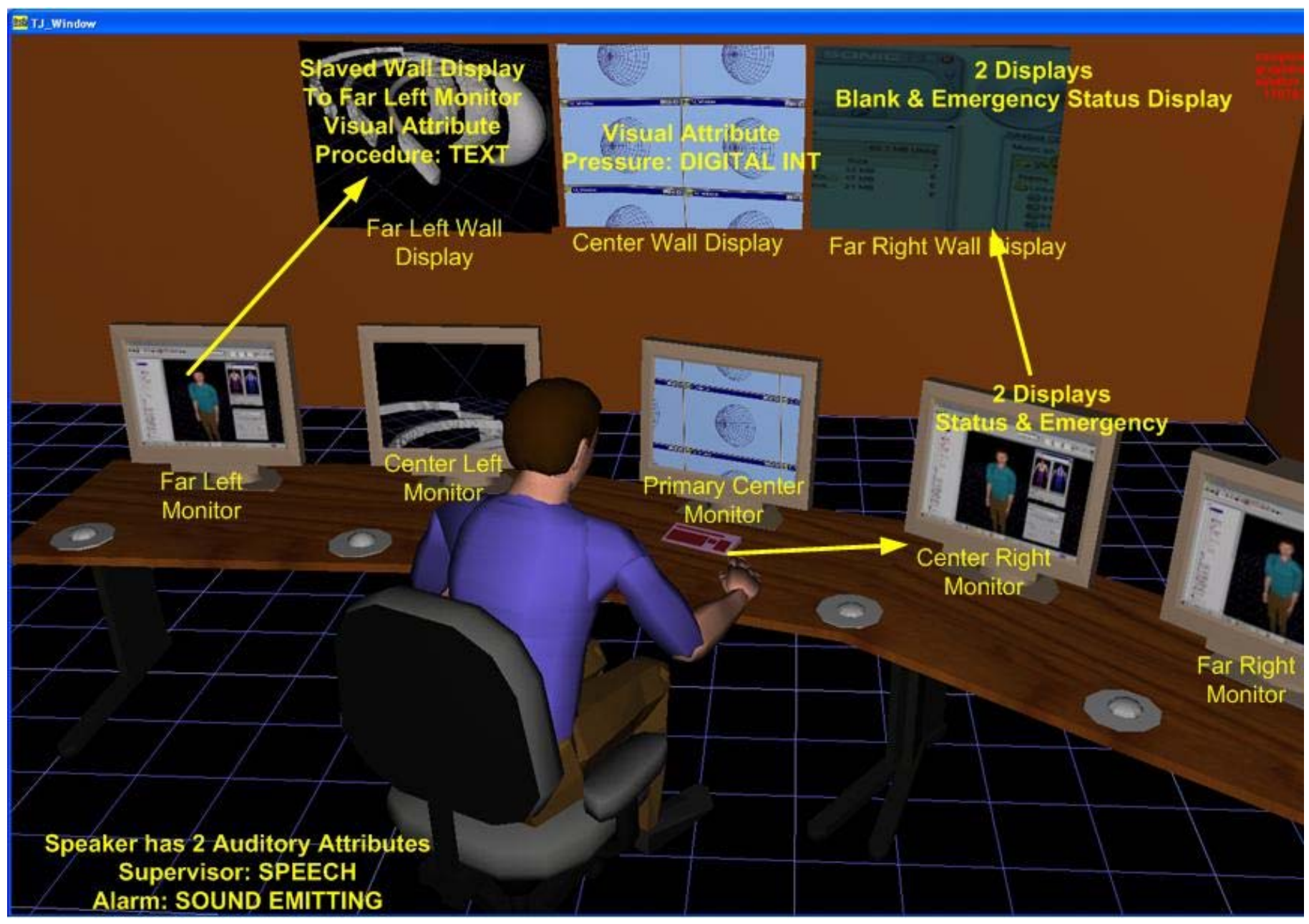

Figure 1. Mockup of control room simulation with virtual control room operator using MIDAS.

(expectancy) and is organized to reduce confusion and alert the operator to abnormal conditions (salience). Additionally, it is possible within MIDAS to represent the crew, whereby each member is modeled to the same level of detail as above. Information is passed between crew members through a model updating process.

Through an interagency agreement, the Idaho National Laboratory (INL) is currently working with NASA Ames Research Center (ARC) to develop this control room simulation capability. These efforts center on incorporating computer aided design (CAD) models of control rooms, modeling advanced instrumentation and functionality in these control rooms, developing realistic crew interaction scenarios, and implementing human reliability analysis logging techniques within MIDAS. The goal of this novel implementation of MIDAS for control rooms is to provide a cost-effective means for screening or pre-testing NGNP control room configurations. Using this simulation environment, it is possible to explore a wide variety of configurations and design concepts prior to hardware design and human crew testing. MIDAS, coupled with human reliability analysis models, will potentially allow the INL and ARC to screen potential nuclear power plant control room configurations and scenarios that would result in suboptimal crew performance. Suboptimal configurations and scenarios would be flagged for more detailed subsequent study using human crews in control room simulators. Thus, the intent is to provide virtual human-in-the-loop testing followed by actual humans in the loop. In both cases, it will be possible to provide crew performance information that can be used to support a variety of human performance and human reliability analysis methods. This paper highlights the proposed simulation usage emerging from this joint development effort between INL and ARC.

\section{USES OF MIDAS FOR CONTROL ROOMS}

The key potential uses for MIDAS-based control room simulations are:

- the estimation of human error with advanced control room equipment and configurations; 
- the investigative determination of contributory cognitive factors for risk significant scenarios involving control room operating crews; and

- the certification of reduced staffing levels in advanced control rooms..

These areas are explicated throughout the remainder of this paper.

\section{ESTIMATION OF HUMAN ERROR}

Gore and Smith (2006) have documented the potential of human performance modeling to inform HRA. Currently, MIDAS includes a series of cognitive models that provide an estimation of crew workload across modeled scenarios. Laux and Plott (2007) have demonstrated that workload measures can be incorporated into HRA models. Our initial project efforts are focused on extending this merger of modeling and HRA by incorporating additional performance measures into MIDAS. These initial efforts are currently capturing aspects of human performance along the eight shaping factors modeled in the SPAR-H HRA method (Gertman et al., 2005). These eight performance shaping factors (PSFs) include: the ratio of required time to available time, stress and stressors, task complexity, experience and training, quality of procedures, ergonomics and humanmachine interface, fitness for duty, and work processes. SPAR-H provides assignment levels for each of these PSFs, which have been calibrated to error likelihood rates found across other HRA methods. Modeling these PSFs within MIDAS allows simulation-based assignment of non-nominal levels, which may be mapped to the PSF levels provided in SPAR-H and subsequently quantified to produce an estimated human error probability (HEP). The capability also exists to use these PSFs to influence such factors as time to respond, and likelihood to exceed working and long-term memory capacity, etc. Because MIDAS permits Monte Carlo style multiple runs of scenarios, it is also possible to adopt a frequentist approach to HEP calculation, in which simulated errors may be mapped back to the PSF states at the time the error occurred. PSFs from other methods, including the 15 PSFs identified in the Good Practices for Implementing HRA (Kolaczkowski, et al., 2005), are planned for future implementation. In most cases, these additional PSFs represent a refinement of the SPAR-H PSFs to a greater level of analytic granularity.

The purpose of incorporating human error modeling in MIDAS is developing the ability to estimate the safety of emerging control room equipment and configurations. It is anticipated that in many cases, there is a significant cost advantage to utilizing MIDAS to screen new equipment virtually vs. the cost of configuring a simulator with new equipment and enlisting control room staff to perform representative tasks. We are currently reviewing a number of risk-significant control room scenarios. The main costs associated with a MIDAS implementation are those related to programming the functionality of the control room equipment into the MIDAS simulation as well as those scripting efforts required to "train" the virtual crew to interact with the system. In contrast, an equal programming effort would be required to incorporate the novel equipment into a reconfigurable simulator, plus, in many cases, there would be special training required for control room operators to ensure their proper interaction with the system. Cost savings are also realized through the reduced time to run simulations vs. simulator trials. Because MIDAS can be used to run an unlimited number of scenarios virtually without actual crews, once configuration of the simulations is initiated, results may be produced on an almost instant basis. Further, it is possible to run the simulation through a broad range of scenarios (e.g., a variety of normal and offnormal conditions) that would require extensive testing across multiple testing trials when using actual control room operators in a simulator.

MIDAS-based screening of novel control room equipment and configurations is not a surrogate for testing with actual control room operators. The results produced by MIDAS simulations are inherently limited by the fidelity of the underlying modeling. While MIDAS simulations represent a high-fidelity approximation of the environment, equipment, and human operators involved in the control room, the predictive ability of simulation is hampered by epistemic and aleatory uncertainty-mismatches and shortcomings attributable to lack of a full understanding of the modeling parameters and random variance, respectively. Ongoing improvements to the underlying cognitive and crew-crew interactive modeling included in MIDAS will mitigate epistemic uncertainty, and repeated simulation trials in Monte Carlo fashion can control for much aleatory uncertainty. Nonetheless, it must be emphasized that MIDAS can only be an approximation of actual crew performance. MIDAS serves as a cost effective tool to approximate human performance in control rooms. It is an especially effective tool to screen and rule out novel control room equipment and configurations that are not optimized for safe, efficient, and usable crew utilization. In integrating robust PSF models with MIDAS' underlying cognitive and ergonomic models, it may provide us key insights that help to redesign equipment or configurations to become more safe, efficient, or usable. For that equipment or configuration that is successfully screened through MIDAS simulations, the MIDAS findings should be verified and validated using actual control room operators. In this manner, costly simulator trials using human participants are minimized for exploratory and screening research and implemented primarily for verification and validation.

\section{DETERMINATION OF RISK SIGNIFICANCE IN RECREATING PAST EVENT SCENARIOS}

Incidents at power plants ocurr infrequently and there is often inadequate operations experience to provide data-based quantification of human performance in HRA. Utilities and regulators that must retrospectively determine the risk 
significance of such past events will utilize HRA estimation methods to the extent that they encompass the PSFs and scenarios at play in the event. However, because of the scarcity of available data, it is often necessary to utilize expert estimation techniques, which have historically been fraught with poor inter-analyst reliability (Boring, et al., 2006).

Human performance modeling utilizing MIDAS avoids the shortcomings of applying an HRA quantification method in a poorly suited domain or utilizing expert opinion to arrive at the human contribution to the risk of an event. Instead, scripting a MIDAS scenario that closely matches the past event, it is possible to generate simulation runs with the virtual crew to arrive at an estimate of the frequency with which human performance elevated the risk of the scenario. This method increases the veracity of risk estimation.

Of course, in many cases it may be possible and desirable to perform simulator trials with human control room crews to replicate event scenarios. As noted earlier, such simulator trials may prove costly and time-consuming. The time required for simulator trials for human performance data ultimately limits their utility in risk significance determination, in which timely results may prove critical to the resolution of the incident and continued safe operation of the plant. MIDAS offers an expedient alternative to simulator trials. Further, MIDAS simulations may be used as a first resort for situations in which it would be impractical, unethical, or dangerous to use actual human participants to replicate the past event scenarios.

\section{CERTIFICATION OF CONTROL ROOM STAFFING LEVELS}

Currently regulated staffing levels in plant control rooms are based on the requirements of contemporary reactor designs. With the advent of NGNP control room designs, with a potentially greater emphasis on passive safety systems and autonomously regulated control systems, the role of the control room operators is significantly changed (Dudenhoeffer et al., 2004; Boring, et al., 2005). These updated control room designs will likely decrease the number of simultaneous control room and plant staff required to carry out the safe operation of the plant. Utilities and regulators are actively seeking ways to certify that reduced staff can perform all required plant operations within safe human performance levels (Persensky, et al., 2005).

While no control room design should be certified solely on the basis of simulation data, the inclusion of carefully and realistically modeled simulations serves to validate data acquired using human participants in research studies or operations logging. Factors of particular interest in considering reduced staffing levels include crew performance in terms of cognitive workload, fatigue, and stress during normal and off-normal operations. A MIDAS based simulation of these factors provides an unambiguous mapping of staffing to performance. The advanced control room may thus be designed to prevent circumstances in which a reduced crew contributes to the risk of a plant. Demonstrated problem areas may be effectively mitigated by additional safety systems or by backup staff. The flexible nature of MIDAS simulations affords the opportunity for efficient iteration of designs to arrive at the optimal safe staffing level for novel control room configurations.

\section{DISCUSSION}

In this paper, we have briefly outlined advantages and uses of MIDAS based virtual control room crew modeling for nuclear power plants. Current project efforts have begun to implement HRA modeling capabilities and basic control room layouts within the MIDAS simulation environment. We are also exploring the possibility of linking the virtual environment and crew modeling of MIDAS with advanced plant thermohydraulic models contained in RELAP5 (Ransom, et al., 1982) as well as advanced plant and power grid visualization tools such as the Critical Infrastructure Modeling System (Dudenhoeffer, et al., 2006). The goal of this effort is to realize within the context of NGNP plants the advanced crew modeling capabilities currently utilized within the aerospace industry. These capabilities point the way to more powerful risk modeling and a safer design basis for next generation control rooms.

\section{ACKNOWLEDGEMENTS AND NOTES}

The MIDAS 5.x software augmentations that enable the capability to apply MIDAS to the process control environment were funded by the NextGen-Airspace project, and the paper composition was funded by the NextGenAirportal project. For more information on MIDAS 5.x, the reader is asked to consult the MIDAS web site at http:/hsi.arc.nasa.gov/groups/midas/.

The authors acknowledge the contribution of Donald D. Dudenhoeffer and Bruce P. Hallbert, who were instrumental in completing an earlier version of this paper (see Boring et al., 2006).

Ronald L. Boring is currently employed by Sandia National Laboratories. Tuan Q. Tran is currently employed by Sprint/Nextel. The work was completed while both authors were employed at Idaho National Laboratory. Please address primary correspondence to David Gertman, david.gertman@inl.gov.

This paper was prepared as an account of work sponsored by an agency of the United States Government. Neither the United States Government nor any agency thereof, nor any of their employees, makes any warranty, expressed or implied, or assumes any legal liability or responsibility for any third party's use, or the results of such use, of any information, apparatus, product, or process disclosed in this paper, or represents that its use by such third party would not infringe privately owned rights. 


\section{REFERENCES}

Boring, R.L., Dudenhoeffer, D.D., Hallbert, B.P., \& Gore, B.F. (2006). Virtual power plant control room and crew modeling using MIDAS. Joint Halden Reactor Project and CSNI Special Experts' Group on Human and Organisational Factors Workshop on Future Control Station Designs and Human Perfromance Issues in Nuclear Power Plants, Paper 5.3 (pp. 1-5).

Boring, R.L., Gertman, D.I., Joe, J.C., Blackwood, L.G., Blackman, H.S., \& Brady, B.M. (2006). A simplified expert elicitation guideline. Proceedings of the 8th International Conference on Probabilistic Safety Assessment and Management, Paper PSAM-0089 (pp. 19).

Boring, R.L., Hugo, J., Richard, C.M., \& Dudenhoeffer, D.D. (2005). Human-computer interaction for nextgeneration control rooms. CHI 2005 Conference Proceedings, 206-207.

Boring, R.L., O’Hara, J.M., Hugo, J., Jamieson, G.A., Oxstrand, J., Ma, R., \& Hildebrandt, M. (In press). Human factors and the nuclear renaissance. Proceedings of the 52nd Annual Meeting of the Human Factors and Ergonomics Society.

Dudenhoeffer, D.D., Gertman, D.I., Boring, R.L., \& Marble, J.L. (2004). Transitioning to advanced human-machine interface technologies. Proceedings of the Fourth American Nuclear Society International Topical Meeting on Nuclear Power Plant Instrumentation, Controls, and Human-Machine Interface Technologies, 306-311.

Dudenhoeffer, D.D., Permann, M.R. \& Boring, R.L. (2006). Decision consequence in complex environments: Visualizing Decision Impact. Proceedings of the First Joint Emergency Preparedness and Responses and Robotic and Remote Systems Topical Meeting, 211-218.

Gertman, D., Blackman, H., Marble, J., Byers, J., \& Smith, C. (2005). The SPAR-H human reliability analysis method, NUREG/CR-6883. Washington, DC: US Nuclear Regulatory Commission.

Gore, B.F., \& Jarvis, P.A. (2005). New integrated modeling capabilities: MIDAS' recent Behavioral Enhancements. Proceedings of the 2005 Aerospace Congress, Paper 2005-01-2701.
Gore, B.F., \& Smith, J.D. (2006). Risk assessment and human performance modeling: the need for an integrated approach. International Journal of Human Factors of Modeling and Simulation, 1, 119-139.

Hart, S.G., Dahn, D., Atencio, A., \& Dalal, K.M. (2001). Evaluation and application of MIDAS v2.0. Proceedings of the 2001 Aerospace Congress, Paper 2001-01-2648.

Kolaczkowski, A., Forrester, J., Lois, E., \& Cooper, S. (2004). Good practices for implementing human reliability analysis (HRA), NUREG-1792. Washington, DC: US Nuclear Regulatory Commission.

Laux, L., \& Plott, C. (2007). Using operator workload data to inform human reliability analyses. Official Proceedings of the Joint 8th IEEE Conference on Human Factors and Power Plants and the 13th Annual Workshop on Human Performance / Root Cause / Trending / Operating Experience/Self Assessment, 309-313.

National Research Council. (1997). Digital instrumentation and control systems in nuclear power plants. Washington, DC: National Academy Press.

O’Hara, J.M., Brown, W.S., Lewis, P.M., \& Persensky, J.J. (2002). Human-system interface design review guidelines, NUREG-0700, Rev. 2. Washington, DC: US Nuclear Regulatory Commission.

O’Hara, J.M., Higgins, J.C., Persensky, J.J., Lewis, P.M., \& Bongarra, J.P. (2004). Human factors engineering program reviw model, NUREG-0711, Rev. 2. Washington, DC: US Nuclear Regulatory Commission.

Persensky, J., Szabo, A., Plott, C., Engh, T., \& Barnes, V. (2005). Guidance for assessing exemption requests from the nuclear power plant licensed operator staffing requirements specified in 10 CFR 50.54(m), NUREG1791. Washington, DC: US Nuclear Regulatory Commission.

Ransom, V.H., Wagner, R.J., Trapp, J.A., Carlson, K.E., Kiser, D.M., Kuo, H.-H., Chow, H., Nelson, R.A., \& James, S.W. (1982). RELAP5/MOD1 code manual volume 1: System models and numerical methods, NUREG/CR1826. Washington, DC: US Nuclear Regulatory Commission. 